\title{
Impact of preconditioning protocol on anesthetic-induced cardioprotection in patients having coronary artery bypass surgery
}

\author{
Jan Fräßdorf, MD, ${ }^{\mathrm{a}, \mathrm{b}}$ Andreas Borowski, MD, ${ }^{\mathrm{c}}$ Dirk Ebel, MD, ${ }^{\mathrm{b}, \mathrm{d}}$ Peter Feindt, MD, ${ }^{\mathrm{c}}$ Manuel Hermes, MD, ${ }^{\mathrm{b}}$ \\ Thomas Meemann, MD, ${ }^{\mathrm{b}}$ René Weber, MD, ${ }^{\mathrm{b}}$ Jost Müllenheim, MD, DEAA, ${ }^{\mathrm{e}}$ Nina C. Weber, PhD, ${ }^{\mathrm{a}}$ Benedikt Preckel, MD, MA, \\ DEAA, $^{\mathrm{a}, \mathrm{b}}$ and Wolfgang Schlack, MD, DEAA ${ }^{\mathrm{a}}$
}

Objective: Anesthetic preconditioning may contribute to the cardioprotective effects of sevoflurane in patients having coronary artery bypass surgery. We investigated whether 2 different sevoflurane administration protocols can induce preconditioning in patients having coronary artery bypass.

\begin{abstract}
Methods: Thirty patients were randomly allocated to 1 of 3 groups. All patients received a total intravenous anesthesia with sufentanil $\left(0.3 \mu \mathrm{g}^{-1} \cdot \mathrm{kg} \cdot \mathrm{h}^{-1}\right)$ and propofol as target controlled infusion $(2.5 \mu \mathrm{g} / \mathrm{mL})$. The control group had no further intervention; 10 minutes prior to establishing the extracorporeal circulation, patients of the sevoflurane-I group received 1 minimum alveolar concentration of sevoflurane for 5 minutes. Patients of the sevoflurane-II group received ( 2 times) 5 minutes of sevoflurane, interspersed by 5 -minute washout 10 minutes prior to extracorporeal circulation. Troponin I was measured as marker of cardiac cellular damage.
\end{abstract}

Results: Peak levels of troponin I release were observed at 4 hours after cardiopulmonary bypass and were not affected by 1 cycle of sevoflurane administration (controls: $14 \pm 3 \mathrm{ng} / \mathrm{mL}$ vs sevoflurane-I group, $14 \pm 3 \mathrm{ng} / \mathrm{mL}$ ). Two periods of sevoflurane preconditioning significantly reduced cellular damage compared with controls (peak troponin I level sevoflurane-II group, $7 \pm 2 \mathrm{ng} / \mathrm{mL}$ ).

Conclusion: These data show that sevoflurane-induced preconditioning is reproducible in patients having coronary artery bypass but depends on the preconditioning protocol used.

Supplemental material is available online.

Volatile anesthetics induce pharmacologic preconditioning of the heart (APC). Volatile anesthetics can also provide cardioprotective effects in the ischemia-reperfusion situation of cardiac surgery. ${ }^{1-3}$ To which extent the phenomenon of APC might contribute to the clinical cardioprotection is still a matter of debate. In contrast to the large number of experimental studies investigating APC, mostly focusing on its signal transduction, ${ }^{4}$ only a few clinical studies are available investigating the effects of APC in humans. ${ }^{5}$

From the Department of Anesthesiology, ${ }^{a}$ Academic Medical Center AMC, University of Amsterdam, Amsterdam, The Netherlands; Department of Anesthesiology, ${ }^{\mathrm{b}}$ University Hospital Duesseldorf, Duesseldorf, Germany; Department of Thoracic and Cardiovascular Surgery, ${ }^{\mathrm{C}}$ University Hospital Duesseldorf, Duesseldorf, Germany; Department of Anesthesiology, ${ }^{\mathrm{d}}$ Slingeland Ziekenhuis, Doetinchem, The Netherlands; and Department of Anesthesiology, ${ }^{\mathrm{e}}$ South Tyneside District Hospital, South Shields, United Kingdom.

Part of the work has been presented at the ASA meeting 2005, Atlanta, and at the ASA annual meeting 2004, Las Vegas.

Support was provided from Deutsche Forschungsgemeinschaft (Bonn, Germany, grant No. SCHL 448/5-1), Siemens Medical Solutions Diagnostics (Fernwald, Germany), Abbott GmbH (Wiesbaden, Germany), and institutional resources.

Received for publication Jan 30, 2008; accepted for publication April 6, 2008.

Address for reprints: Benedikt Preckel, MD, MA, DEAA, Academic Medical Center, University of Amsterdam, Postbus 22660 H1Z-120, 1100 DD Amsterdam, The Netherlands (E-mail: b.preckel@amc.uva.nl).

J Thorac Cardiovasc Surg 2009;137:1436-42

$0022-5223 / \$ 36.00$

Copyright (c) 2009 by The American Association for Thoracic Surgery doi:10.1016/j.jtcvs.2008.04.034
The first indirect advice was provided by Belhomme and colleagues in $1999^{6}$; they demonstrated that isoflurane $(2.5$ $\mathrm{Vol} \%$ ) administered before aortic crossclamping in coronary artery bypass graft (CABG) surgery increased the $5^{\prime}$ nucleotidase activity in right atrial tissue, ${ }^{6}$ a marker of protein kinase $\mathrm{C}$ (PKC) activation, which is a central step in APC in experimental studies. ${ }^{7}$ However, a decrease in myocardial injury as measured by troponin I ( $\mathrm{TnI})$ or creatine kinase (CK)-MB release was not observed. ${ }^{6} \mathrm{~A}$ more recent study investigated if sevoflurane $(4 \mathrm{Vol} \%)$ can induce preconditioning in CABG patients. ${ }^{8}$ There was no washout of the volatile anesthetic before ischemia in this study (which is by definition a prerequisite for the preconditioning phenomenon). Again, no differences regarding myocardial injury as measured by CK-MB and troponin-T release were observed. These results suggest that APC might be present in humans, but the effect is still inconsistent. A significant inhomogeneity in the experimental setup is evident in clinical APC studies, using different time periods of APC, ${ }^{9}$ different concentrations of volatile anesthetics, ${ }^{8}$ and inclusion of a washout period ${ }^{6}$ or not. ${ }^{8}$

In animal studies, myocardial protection by ischemic preconditioning (IPC) is strengthened by multiple cycles of short ischemia and reperfusion. ${ }^{10}$ In multiple cycles of IPC, it is necessary to inhibit different parallel pathways to block cardioprotection (eg, $\mathrm{PKC}$ as well as protein tyrosine kinase), whereas in single-cycle IPC, the cardioprotection is completely abolished by blocking only 1 of these 2 kinases. ${ }^{10}$ Multiple cycles of sevoflurane preconditioning in a rat model in vivo strengthened the cardioprotective effect of APC. ${ }^{11}$ 


\begin{tabular}{|c|c|}
\hline \multicolumn{2}{|c|}{ Abbreviations and Acronyms } \\
\hline APC & $\begin{array}{c}=\text { anesthetic-induced pharmacologic } \\
\text { preconditioning of the heart }\end{array}$ \\
\hline BNP & $=$ brain natriuretic peptide \\
\hline CABG & $=$ coronary artery bypass graft \\
\hline $\mathrm{CI}$ & $=$ cardiac index \\
\hline $\mathrm{CK}$ & $=$ creatine kinase \\
\hline $\mathrm{CPB}$ & $=$ cardiopulmonary bypass \\
\hline CVP & $=$ central venous pressure \\
\hline $\mathrm{dP} / \mathrm{dt}_{\max }$ &  \\
\hline EuroSCC & $=$ European System for Cardiac \\
\hline & Operative Risk Evaluation \\
\hline ICU & $=$ intensive care unit \\
\hline IPC & $=$ ischemic preconditioning \\
\hline LV & $=$ left ventricular \\
\hline MAC & $=$ minimum alveolar concentration \\
\hline MAP & $=$ mean arterial pressure \\
\hline PKC & $=$ protein kinase $\mathrm{C}$ \\
\hline TnI & $=$ troponin I \\
\hline
\end{tabular}

We hypothesized that the concept of APC is applicable in the setting of CABG procedures in humans but might depend on the preconditioning protocol. We looked for myocardial injury (cardiac TnI release) and myocardial function as measured by intraventricular tip manometer after application of 1 or 2 cycles of sevoflurane preconditioning in patients having CABG surgery.

\section{METHODS}

The study was performed according to the Declaration of Helsinki principles. The Ethical Committee of the Heinrich-Heine-University Düsseldorf, Germany approved the study, and written informed consent was obtained from each patient. Patients having isolated coronary revascularization were included. Exclusion criteria were physical American Society of Anesthesiology status 4 or 5, angina during the previous 72 hours, unstable angina, acute myocardial infarction, ejection fraction lower than $40 \%$, congestive heart failure, emergency procedures, former CABG surgery, concurrent valve repair, oral antidiabetics, or theophylline therapy. Cardiac operative risk was calculated using the European System for Cardiac Operative Risk Evaluation (EuroSCORE). ${ }^{12}$

Patients were randomly (by using sealed envelopes) allocated to the control (no further specific treatment), SEVO-I or SEVO-II group. Ten minutes prior to establishing cardiopulmonary bypass (CPB), patients of the SEVO-I group received 1 minimum alveolar concentration (MAC) of sevoflurane (2 $\mathrm{Vol} \%$ ) for 5 minutes. Patients of the SEVO-II group received 2 cycles of 1 MAC sevoflurane for 5 minutes, interspersed by 5 -minute washout, 10 minutes prior to establishing CPB (see Figure 1).

\section{Anesthesia, Surgery, and Study Protocol E1). \\ The detailed information is available as an online supplement (Appendix \\ Acetylsalicylic acid therapy was discontinued 1 week prior to surgery; all other preoperative medications were continued until the morning of the op-} eration. Patient monitoring included continuous 5-lead electrocadiographic registration with ST-segment analysis (leads II and V5), pulse oximetry, invasive radial artery blood pressure measurement, central venous pressure (CVP), pulmonary artery catheters with continuous mixed venous saturation and cardiac output measurement (CCOmbo, Edwards Lifescience, Irvine, CA), capnography, rectal temperature, and urine output.

Anesthesia was induced and maintained with propofol target-controlled infusion with a plasma target concentration of $2.5 \mu \mathrm{g} / \mathrm{mL}$ plasma, sufentanil $\left(0.3 \mu \mathrm{g} \cdot \mathrm{kg}^{-1} \cdot \mathrm{h}^{-1}\right)$ and pancuronim bromide $(0.1 \mathrm{mg} / \mathrm{kg})$.

Myocardial revascularization was performed according to the standard procedure of the University of Düsseldorf by a single surgeon (A.B.) with warm $\left(34^{\circ} \mathrm{C}\right)$ blood cardioplegia.

According to the study protocol, norepinephrine was used to keep mean arterial pressure (MAP) above $70 \mathrm{~mm} \mathrm{Hg}$, and dobutamine was used to maintain cardiac index $(\mathrm{CI})$ above $2.5 \mathrm{~L} \cdot \mathrm{min}^{-1} \cdot \mathrm{m}^{-2}$. An overview of the time points of hemodynamic measurements and blood sampling is given in Figure 1.

Patients, surgeon, and perfusionists were blinded regarding the enrollment into the study groups. After surgery, patients were transferred to the intensive care unit (ICU) and received routine therapy, including fast weaning from the ventilator. All decisions regarding medical care on the ICU and the ward after the operation were done by physicians and nurses blinded to the study protocol.

\section{Hemodynamic Data Analysis}

Global hemodynamic variables (MAP, CVP, pulmonary artery pressure, pulmonary artery occlusion pressure, $\mathrm{CI}$, and heart rate) were measured at regular time points (see Figure 1). Additionally, we assessed left ventricular (LV) performance in terms of systolic (LV peak systolic pressure and maximum rate of $\mathrm{LV}$ pressure increase $\left[\mathrm{dP} / \mathrm{dt}_{\max }\right]$ ) and diastolic function (time constant of $\mathrm{LV}$ isovolumetric relaxation). $\mathrm{dP} / \mathrm{dt}$ was direct calculated by the computer system (PowerLab, ADInstruments, Spechbach, Germany). Enddiastolic pressure was timed at the beginning of the sharp upslope of the LV $\mathrm{dP} / \mathrm{dt}$ tracing. Mixed venous saturation and CI were measured continuously and recorded at regular intervals.

\section{Biochemical Analysis}

In all patients, blood samples were taken at time points $\mathrm{T} 1$ (baseline), $\mathrm{T} 7$ (10 minutes post-CPB), T12 (4 hours post-CPB), T14 (12 hours post-CPB), T15 (24 hours post-CPB), T16 (48 hours post-CPB), and T17 (72 hours post-CPB, see Figure 1). We measured cardiac TnI, CK and its myocardial specific isoform CK-MB, and brain natriuretic peptide (BNP) as markers of cellular injury and myocardial dysfunction, respectively. Blood samples were centrifuged and plasma was stored at $-80^{\circ} \mathrm{C}$ until measurement. TnI (microparticle enzyme immunoassay, Abbott, Wiesbaden, Germany), CK and CK-MB analyses were performed in our routine laboratory, and measurement of BNP levels were done by Siemens Medical Solutions Diagnostics (Fernwald, Germany). Institutional threshold values for TnI are $\leq 0.4$ $\mathrm{ng} / \mathrm{mL}$ as reference value, 0.5 to $2.0 \mathrm{ng} / \mathrm{mL}$ for suspicious myocardial ischemia, and $\geq 2.0 \mathrm{ng} / \mathrm{mL}$ for suspicious myocardial infarction.

\section{Tissue Fractionation and Western Blot Analysis}

Tissue fractionation and subsequent Western blot assay off shock-frozen right atrial tissue was performed as previously described. ${ }^{13}$ Cytosolic (P1), membrane (P2), and the particulate fraction (P3) were electroblotted using the respective first antibody for the phosphorylated and total PKC isoforms $\alpha\left(\mathrm{PKC}_{\alpha}\right)$ and $\epsilon\left(\mathrm{PKC}_{\epsilon}\right)$ and the phosphorylated Src kinase (tyrosine 416). For detection of total $\mathrm{PKC}_{\epsilon}$, we used anti-PKC $\mathrm{PK}_{\epsilon}$ antibody (1:10000; Upstate


(1:10000, Upstate); for total $\mathrm{PKC}_{\alpha}$, anti-PKC $(1: 10000$, Upstate); for phospho-PKC $\mathrm{P}_{\alpha}$, anti-phospho-PKC ${ }_{\alpha}(1: 10000$, Upstate); and for phospho-Src, the corresponding antibody (1:10000, Cell Signalling, Danvers, MA). As internal standard we used antibodies against $\alpha$-tubulin (1:50000, Sigma, Taufkirchen, Germany) in total $\mathrm{PKC}_{\alpha}$ and $\mathrm{PKC}_{\epsilon}$ analysis, or actin (1:10000, Sigma, Taufkirchen, Germany) in phospho-Src blots, respectively. 




FIGURE 1. Experimental protocol; T0 to T17 time points of measurements (hemodynamic and/or laboratory samples). AOX, Aortic crossclamping (= myocardial ischemia); $C P B$, cardiopulmonary bypass; $T C I$, target-controlled infusion of propofol; $M A C$, minimum alveolar concentration; $O P$, operative; $I C U$, intensive care unit. Sevo I group received 1 minimum alveolar concentration of sevoflurane for 5 minutes before cardiopulmonary bypass; Sevo II group received ( 2 times) 5 minutes of sevoflurane, interspersed by 5 -minute washout 10 minutes prior to extracorporeal circulation.

\section{Statistical Analysis}

Primary end point of the study was reduction of myocardial damage in terms of TnI release. Sample size calculation was based on the assumption that the $\mathrm{SD}$ of the means of the TnI plasma levels will be $4.5 \mathrm{ng} / \mathrm{mL}, \alpha=$ 0.05 , and $\beta=0.8$. A sample size of 10 patients in each group was necessary to detect a difference of the means of $40 \%$ (GraphPad StatMate, San Diego, CA).

All data were tested for normal distribution (GraphPad Prism 4 for Windows, Graph Pad). Categorical data were analyzed by using Fisher exact test. Parametric data were analyzed by using a 2-way analysis of variance followed by Dunnett test as post hoc test with reference to the control group for group effects and to baseline measurements for time effects. Data are presented as mean \pm standard deviation or median and range.

\section{RESULTS}

There were no significant differences regarding preoperative demographic data and predicted additive risk determined by EuroSCORE, which showed a medium risk in all groups (Table 1). The number of bypass grafts and duration of aortic crossclamping were similar in all 3 groups (Table 1). Lengths of postoperative intubation, postoperative stay in the ICU, as well as length of hospital stay were not different between controls and interventional groups (Table 1).

Global hemodynamics were not different during baseline or at the end of the observation period ( 24 hours post-CPB; T15; Table E1). Before starting CPB, we observed a reduced heart rate and an increased pulmonary artery wedge pressure in the SEVO-II group compared with control group. At T13, an increased CI in SEVO-II group compared with the control group was seen, but this effect was abrogated at T15. In both SEVO groups, CI was increased compared with baseline values. $\mathrm{dP} / \mathrm{dt}_{\max }$ was increased in the SEVO-II group 10 minutes after $\mathrm{CPB}$, as well as the LV pressures (see Table 2). Heart rate was increased in all patients after CPB due to external cardiac pacing.

TnI plasma concentrations were reduced in SEVO-II patients compared with SEVO-I patients and control group (see Figure 2). Regarding CK, CK-MB, and BNP, no significant differences between the groups were detected (Table E2).

Although no change in phosphorylation of PKC $\epsilon$ after APC was determined (ratio phospho PKC $\epsilon /$ total PKC $\epsilon$ : control group, before APC $0.34 \pm 0.1$, after APC $0.34 \pm 0.14$; SEVO-I group, $0.33 \pm 0.1$ vs $0.34 \pm 0.1$; SEVO-II group, $0.3 \pm 0.1$ vs $0.31 \pm 0.1$ ), translocation of PKC $\epsilon$ to the particular fraction of the right atrial tissue was observed in the SEVO-II group (ratio total PKC $\epsilon$ after APC to before APC: P1 $1.1 \pm 0.2 ; \mathrm{P} 21.0 \pm 0.1 ; \mathrm{P} 32.5 \pm 1.4 ; P<.001$ vs $\mathrm{P} 1$ and P2), but not in the SEVO-I group (P1 $1.1 \pm 0.3$; $\mathrm{P} 21.2 \pm 0.4 ; \mathrm{P} 31.6 \pm 0.7)$ or in the control group (P1 $1.1 \pm 0.4 ; \mathrm{P} 21.0 \pm 0.3 ; \mathrm{P} 31.1 \pm 0.3$ ). 
TABLE 1. Patient characteristics

\begin{tabular}{|c|c|c|c|}
\hline & $\begin{array}{l}\text { Control } \\
(\mathbf{n}=10)\end{array}$ & $\begin{array}{l}\text { SEVO-I } \\
(\mathbf{n}=10)\end{array}$ & $\begin{array}{c}\text { SEVO-II } \\
(\mathbf{n}=10)\end{array}$ \\
\hline \multicolumn{4}{|l|}{ Preoperative data } \\
\hline $\operatorname{Sex}(M / F)$ & $9 / 1$ & $9 / 1$ & $9 / 1$ \\
\hline Age (y) & $66 \pm 8$ & $65 \pm 9$ & $67 \pm 8$ \\
\hline BMI $\left(\mathrm{kg} / \mathrm{m}^{2}\right)$ & $30 \pm 4$ & $26 \pm 4$ & $29 \pm 3$ \\
\hline EuroSCORE, median/range & $4(3-8)$ & $4(0-7)$ & $5(0-6)$ \\
\hline \multicolumn{4}{|l|}{ Preoperative medication } \\
\hline ACE inhibitor & 7 & 7 & 8 \\
\hline ASS & 0 & 0 & 0 \\
\hline Bronchodilating agents & 1 & 1 & 1 \\
\hline $\mathrm{Ca}^{2+}$ antagonists & 1 & 1 & 2 \\
\hline Diuretics & 4 & 3 & 5 \\
\hline Heparin & 7 & 6 & 7 \\
\hline Insulin & 0 & 0 & 0 \\
\hline Molsidomine & 1 & 5 & 2 \\
\hline Nitrates & 3 & 3 & 2 \\
\hline ß-blocker & 8 & 8 & 7 \\
\hline Statin & 6 & 6 & 7 \\
\hline Theophylline & 0 & 0 & 0 \\
\hline \multicolumn{4}{|l|}{ Intraoperative data } \\
\hline No. of bypass (median/range) & $4(2-4)$ & $3(2-4)$ & $4(2-5)$ \\
\hline CPB time (min) & $98 \pm 29$ & $95 \pm 26$ & $95 \pm 23$ \\
\hline Aortic crossclamp time (min) & $52 \pm 18$ & $52 \pm 12$ & $51 \pm 18$ \\
\hline Reperfusion time (min) & $39 \pm 14$ & $37 \pm 13$ & $41 \pm 9$ \\
\hline \multicolumn{4}{|l|}{ Postoperative data } \\
\hline Length of intubation (min) & $348 \pm 191$ & $306 \pm 166$ & $296 \pm 166$ \\
\hline Length of stay ICU (h) & $25 \pm 8$ & $22 \pm 4$ & $21 \pm 1$ \\
\hline Length of stay hospital (d) & $15 \pm 5$ & $13 \pm 6$ & $12 \pm 5$ \\
\hline
\end{tabular}

BMI, Body mass index; EuroSCORE, European System for Cardiac Operative Risk Evaluation; $A C E$, angiotensin-converting enzyme; ASS, acetylsalicylic acid (ASS was withdrawn in all patients); $C a^{2+}$ antagonist, calcium channel antagonists; $C P B$, cardiopulmonary bypass; $I C U$, intensive care unit.

Neither PKC $\alpha$ (ratio phospho-PKC $\alpha /$ total-PKC $\alpha$ Con before APC $0.6 \pm 0.14$, after APC $0.64 \pm 0.15$; SEVO-I group $0.59 \pm 0.1$ vs $0.59 \pm 0.12$ and SEVO-II group $0.56 \pm 0.11$ vs $0.61 \pm 0.21$; ratio total PKC $\alpha$ before vs after APC: control group, $\mathrm{P} 11.0 \pm 0.2, \mathrm{P} 20.96 \pm 0.1, \mathrm{P} 30.94 \pm 0.2$; SEVO-I group, P1 $0.98 \pm 0.1, \mathrm{P} 20.98 \pm 0.2, \mathrm{P} 30.91 \pm$ 0.3; SEVO-II group, P1 $1.06 \pm 0.1, \mathrm{P} 21 \pm 0.1, \mathrm{P} 30.97$ \pm 0.1 ) nor tyrosine kinase Src (ratio phospho-Src before vs after APC, control group $0.95 \pm 0.3$, SEVO-I group $0.91 \pm 0.2$, SEVO-II group $0.86 \pm 0.3$ ) was activated by sevoflurane administration.

\section{DISCUSSION}

Previous studies indicated that volatile anesthetics have direct cardioprotective properties, independent of hemodynamic or metabolic changes. ${ }^{14}$ In experimental in vitro and in vivo models, volatile anesthetics have been shown to precondition the heart, thereby protecting the myocardium against infarction and postischemic dysfunction. ${ }^{4,7,15} \mathrm{We}$ demonstrated in the present study that APC can be achieved in humans by 1 MAC sevoflurane; however, the cardioprotection depends on the preconditioning protocol. Reduction of cellular damage goes along with improvement of myocardial function early after termination of extracorporeal circulation.

Several studies have addressed the potential clinical implication of cardioprotection by volatile anesthetics in coronary artery surgery patients, looking on cellular enzyme release and myocardial function. ${ }^{1,2,8,16}$ Although some studies show beneficial effects of volatile anesthetics, others do not, leaving the concept of APC in humans questionable. This is in strong contrast to animal studies and might be caused by the different methods of the clinical investigations. Preconditioning includes a short stimulus (ischemic or pharmacologic stimulus), followed by definition by a short reperfusion or washout period of the pharmacologic stimulus, respectively. ${ }^{17}$ Therefore, to fulfill the criteria of preconditioning, the volatile anesthetic must not be present at the onset of sustained myocardial ischemia. There are only a few clinical studies that meet this criteria. Belhomme and colleagues ${ }^{6}$ used high-dose isoflurane $(2.5 \mathrm{Vol} \%)$ for 15 minutes followed by a 10-minute washout period before aortic crossclamping. They demonstrated an increase in $5^{\prime}$ nucleotidase activity (a marker of PKC activity) in right atrial tissue but could not show significant reduction of TnI or CK-MB release. Tomai and associates ${ }^{18}$ used a stimulus of 15 minutes of isoflurane followed by 10-minute washout before $\mathrm{CPB} .{ }^{18}$ They could not detect differences regarding myocardial function and cellular enzyme release between the control and the study group (20 patients in each group). Similar results were obtained from a second study of this group in diabetic patients. ${ }^{19}$ Piriou and colleagues ${ }^{20}$ investigated 72 patients in a 2-center, randomized study. APC was induced with sevoflurane for 15 minutes (1 MAC) followed by 15 -minute washout prior to CPB and myocardial ischemia. They did not observe a reduction in TnI. There was no difference in the activity of PKC, tyrosinkinase, or mitogen-activated protein kinase p38. But in the APC group, they observed fewer patients with low cardiac output. De Hert and associates ${ }^{9}$ investigated if the timing of the sevoflurane administration is crucial for the sevoflurane-induced cardioprotection. They administered sevoflurane after sternotomy until the start of CPB at a dose between 0.5 and $2.0 \mathrm{Vol} \%$ (preconditioning group), from the begin of reperfusion until the end of the procedure (postconditioning group), or throughout the entire procedure (sevoflurane for all); patients of the control group were anesthetized with propofol. In the preconditioning and the postconditioning group, the authors observed a trend to lower TnI plasma levels after the CABG procedure in their patients, but a significant reduction of this biomarker for myocardial damage was determined only in the sevoflurane for all group. ${ }^{9}$ As it is known from experimental data, where multiple preconditioning cycles exert stronger cardioprotective effects 
TABLE 2. Myocardial function

\begin{tabular}{|c|c|c|c|c|c|c|c|}
\hline & Baseline (T1) & SEVO-I (T2) & WASH-I (T3) & SEVO-II (T4) & WASH-II (T5) & 3 min post-CPB (T6) & $10 \mathrm{~min}$ post-CPB (T7) \\
\hline \multicolumn{8}{|c|}{$\operatorname{LVP}_{\text {MAX }}(\mathrm{mm} \mathrm{Hg})$} \\
\hline $\mathrm{CON}$ & $91 \pm 20$ & & & & $90 \pm 31$ & $100 \pm 13$ & $99 \pm 19$ \\
\hline SEVO-I & $106 \pm 11$ & $85 \pm 13 \dagger$ & & & $101 \pm 11$ & $97 \pm 14$ & $103 \pm 16$ \\
\hline SEVO-II & $106 \pm 8$ & $94 \pm 13$ & $105 \pm 16$ & $94 \pm 14$ & $101 \pm 8$ & $121 \pm 13^{*}$ & $120 \pm 21$ \\
\hline \multicolumn{8}{|c|}{$\mathrm{LVP}_{\mathrm{ED}}(\mathrm{mm} \mathrm{Hg})$} \\
\hline $\mathrm{CON}$ & $12.6 \pm 3$ & & & & $12.6 \pm 3$ & $16.2 \pm 4$ & $15.0 \pm 3$ \\
\hline SEVO-I & $13.0 \pm 3$ & $11.8 \pm 3$ & & & $12.7 \pm 3$ & $19.0 \pm 9 \dagger$ & $15.6 \pm 3$ \\
\hline SEVO-II & $17.0 \pm 3^{*}$ & $15.4 \pm 2$ & $17.3 \pm 4$ & $16.5 \pm 4$ & $15.0 \pm 4$ & $21.4 \pm 5^{*}$ & $19.7 \pm 5^{*}$ \\
\hline \multicolumn{8}{|c|}{$\mathrm{dP} / \mathrm{dt}_{\max }(\mathrm{mm} \mathrm{Hg} / \mathrm{s})$} \\
\hline $\mathrm{CON}$ & $872 \pm 211$ & & & & $830 \pm 200$ & $1130 \pm 555$ & $916 \pm 208$ \\
\hline SEVO-I & $1042 \pm 325$ & $938 \pm 280$ & & & $1055 \pm 330$ & $1173 \pm 475$ & $1441 \pm 508$ \\
\hline SEVO-II & $1015 \pm 165$ & $874 \pm 190$ & $1058 \pm 238$ & $892 \pm 206$ & $1016 \pm 179$ & $1447 \pm 363 \dagger$ & $1735 \pm 584 * \dagger$ \\
\hline \multicolumn{8}{|l|}{$\tau(\mathrm{ms})$} \\
\hline $\mathrm{CON}$ & $54 \pm 15$ & & & & $57 \pm 17$ & $46 \pm 20$ & $53 \pm 33$ \\
\hline SEVO-I & $58 \pm 15$ & $67 \pm 11$ & & & $61 \pm 20$ & $58 \pm 30$ & $48 \pm 16$ \\
\hline SEVO-II & $57 \pm 15$ & $64 \pm 20$ & $58 \pm 13$ & $62 \pm 20$ & $52 \pm 10$ & $44 \pm 12$ & $45 \pm 17$ \\
\hline
\end{tabular}

$L V P_{M A X}$, Maximal left ventricular pressure; $L V P_{E D}$, end-diastolic left ventricular pressure; $d P / d t_{\max }$, maximal rate of pressure change of the left ventricular pressure; $\tau$, time constant of decrease in left ventricular isovolumic pressure; $C P B$, cardiopulmonary bypass; $C O N$, control group. For explanation of the time points and groups, see Figure 1; data are mean \pm standard deviation. $* P<.05$ versus control group; $\nmid P<.05$ versus baseline.

compared with single-cycle preconditioning protocols, ${ }^{10}$ we investigated whether multiple cycles are able to induce APC in humans having CABG procedures. Our data now show for the first time that reduction of cellular damage accompanied by improvement of early recovery of myocardial function depends on the preconditioning protocol: although one cycle of sevoflurane administration was not protective, 2 cycles reduced the cellular damage.

Other clinical studies either used no preischemic washout or applied the volatile anesthetic before and after CPB or during the whole surgical procedure. Accordingly, these studies might also have included cardioprotective effects other than preconditioning (ie, effects during ischemia or during reperfusion [postconditioning]). Julier and colleagues ${ }^{8}$ applied a high dose of sevoflurane $(4 \mathrm{Vol} \%)$ while the patient was already connected to the CPB and did not include a washout period. They found no differences in TnI release between groups, but they observed a decrease of pro $\mathrm{N}$ terminal (NT) brain natriuretic peptide (BNP) (pro-NT-BNP), a marker of myocardial dysfunction, after sevoflurane pretreatment and a translocation of PKC- $\delta$ to the sarcolemma and of PKC- $\epsilon$ to mitochondria, intercalated discs, and the cell nucleus in right atrial tissue. Due to the high sevoflurane concentration, they had to administer phenylephrine to maintain perfusion pressure. Phenylephrine infusion as well as CPB might also induce a preconditioning effect, ${ }^{21}$ thereby probably masking protective effects of sevoflurane administration. In contrast to this study, we demonstrated a reduction of TnI after 2 cycles of sevoflurane preconditioning, but there was no reduction of BNP (see Figure 2 and Table E2). We observed a translocation of PKC $-\epsilon$ from the cytosolic fraction to the particulate fraction that contains the nuclei of the right atrial cells. These differences might be explained by the different protocols used. In addition, Julier and colleagues ${ }^{8}$ used aprotinin in their patients, and we did not. Aprotinin is a protease inhibitor that in animal experiments can abolish 1-, 2-, and 3-cycle

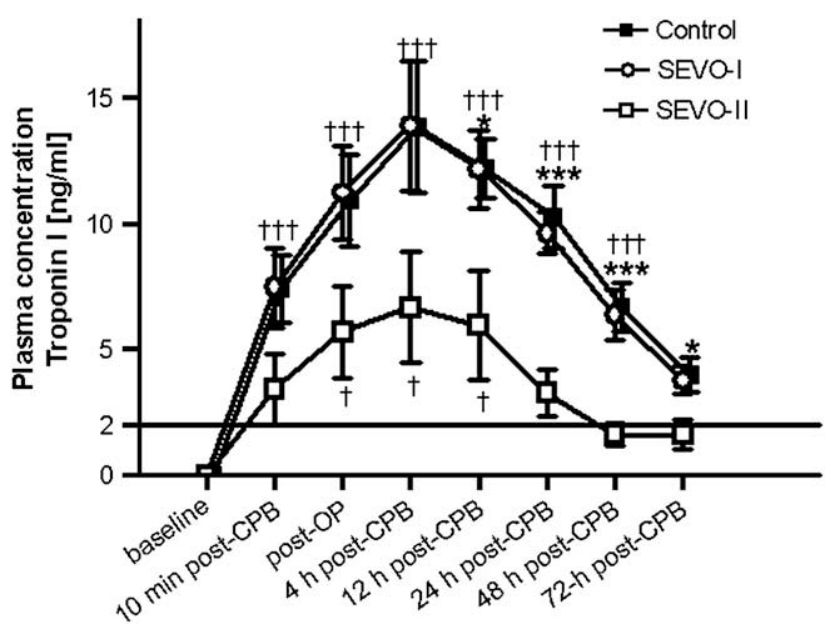

FIGURE 2. Plasma concentrations of troponin I during the observation period of the study. The horizontal line marks the level of positive values for troponin I representing myocardial infarction. SEVO-I group received 1 minimum alveolar concentration of sevoflurane for 5 minutes before CPB; SEVO-II group received (2 times) 5 minutes of sevoflurane, interspersed by 5 -minute washout 10 minutes prior to extracorporeal circulation and CPB. Control patients were not treated with sevoflurane. Data are mean \pm standard deviation. $\dagger \dagger \dagger P<.001$ versus baseline (control and SEVO-I group), $\dagger P<.05$ versus baseline (SEVO-II group); $* P<.05, * * * P<$ .001 control and SEVO-I group versus SEVO-II group at corresponding time points. $C P B$, Cardiopulmary bypass. 
APC by sevoflurane. ${ }^{11}$ This might have influenced the cardioprotective effects of volatile anesthetics in previous clinical studies. ${ }^{8,9}$

Besides aprotinin, which is a very strong blocker of preconditioning and was avoided in the present study, patients might face a variety of other factors that partially can block preconditioning in animal experiments, like elevated glucose levels, ${ }^{22}$ intake of oral antidiabetics, ${ }^{23}$ or beta-adrenoceptor blockers. $^{24}$ In our study, most patients were on beta-blocker and mean glucose increased to $145 \mathrm{mg} / \mathrm{dL}$ during CPB. One might speculate that a partial blockade of the preconditioning mechanism by these factors could explain the presence of only 1 activation way of PKC (ie, only translocation of the enzyme) and the need for a stronger stimulus to induce organ protection. In IPC, multiple cycles of preconditioning ischemia are more protective than a single cycle, ${ }^{10}$ and our data support that this concept of a stronger stimulus to protect the heart is also observed in APC. Other perioperative factors that might influence the ischemia-reperfusion injury were similar in our patients. All patients were completely revascularized, each anastomosis was performed during 1 cycle of blood cardioplegia according to the technique of Calafiori, all operations were performed by the same surgeon, and no intermittent reperfusion was used. As different levels of anesthesia during the preconditioning protocol might lead to a better oxygen demand-supply ratio, we stopped for the preconditioning procedure (ie, sevoflurane administration) the propofol application and maintained in our patients the same depth of anesthesia in terms of bispectral index (BIS) levels (at T2, control group: $32 \pm 7$, SEVO-I group: $31 \pm 8$, SEVO-II group: $30 \pm 10$; T4, control group: $32 \pm 6$, SEVO-I group: $32 \pm 5$, SEVO-II group: $34 \pm 8$ ). To estimate the additive patient risk, we calculated the EuroSCORE for each patient with an equal distribution of EuroSCOREs within the groups (Table 1). As no differences in perioperative factors are obvious, we conclude that the observed effect is most likely due to the administration of sevoflurane.

We did not measure plasma or myocardial levels of sevoflurane but measured routine end-tidal sevoflurane concentration in our patient. Using a high fresh gas flow during the preconditioning period, we were able to achieve fast washin and washout of the volatile anesthetic (in every patient we achieved a measured level of $0 \%$ in the end-tidal respiratory gas, measured at 5 minutes after sevoflurane administration).

Other clinical studies investigating volatile anesthetic-induced cardioprotection in CABG patients applied the substances either before or after ischemia or during the whole surgical procedure, probably combining different cardioprotective effects like pre- and postconditioning. There is evidence that the most uniform cardioprotective effect can be achieved when the volatile anesthetic (eg, sevoflurane) is administered throughout the surgical procedure. ${ }^{9}$ Multicenter, randomized clinical trials demonstrated cardioprotective ef- fects of desflurane in $\mathrm{CABG}$ surgery with $\mathrm{CPB}^{2}$ as well as in patients subjected to off-pump coronary artery grafting. ${ }^{1}$ In contrast, a single-center study including 18 patients failed to show beneficial effects of sevoflurane-based anesthesia compared with propofol-based anesthesia at comparable bispectral levels. ${ }^{25}$ De Hert and colleagues ${ }^{9,26}$ showed in different studies that inhalational anesthetics are beneficial compared with intravenous anesthetics in CABG surgery patients. However, administration of sevoflurane only before or after myocardial ischemia was less effective compared with administration of the volatile anesthetic throughout the procedure ${ }^{9}$; the later resulted in reduced length of stay on the ICU and in the hospital.

One might ask what will happen if we give 10 minutes of sevoflurane instead of 2 times 5 minutes prior to CPB. This question cannot be answered by our study. We have decided to increase the number of stimuli, because from animal studies it is well known that multiple cycles of IPC enhance the cardioprotection from ischemic- and anesthetic-induced preconditioning. Additionally, other groups tried with higher concentration $^{8}$ or longer administration ${ }^{9}$ to precondition the myocardium but failed to show clear cardioprotective effects.

We used cardiac TnI as biomarker for myocardial damage, which has high myocardial tissue specificity and high sensitivity, reflecting even very small amounts of myocardial necrosis ${ }^{27}$ and irreversible cell injury in surgical patients. $^{28}$ Cardiac TnI might predict short- and long-term outcome after CABG surgery. ${ }^{29}$ However, our study was not designed and powered to measure short- or long-term outcome after CABG surgery, allowing no conclusion on patient outcome after myocardial preconditioning with volatile anesthetics. In contrast to a previous study, ${ }^{8}$ we did not observe significant differences in BNP levels between the groups. This discrepancy might be caused by different methodologies used in both studies as discussed earlier.

Recent meta-analyses demonstrated that the newer volatile anesthetics sevoflurane and desflurane reduce postoperative rise in cardiac $\mathrm{TnI}^{3}$ and result in decreased morbidity and mortality. ${ }^{30}$ The present study demonstrates for the first time that a preconditioning effect of sevoflurane in patients having $\mathrm{CABG}$ depends on the preconditioning protocol.

We thank Yvonne Grüber, technician, Department of Anesthesiology, University Hospital of Düsseldorf, Düsseldorf, Germany, for excellent technical support.

\section{References}

1. Guarracino F, Landoni G, Tritapepe L, Pompei F, Leoni A, Aletti G, et al. Myocardial damage prevented by volatile anesthetics: a multicenter randomized controlled study. J Cardiothorac Vasc Anesth. 2006;20:477-83.

2. Tritapepe L, Landoni G, Guarracino F, Pompei F, Crivellari M, Maselli D, et al. Cardiac protection by volatile anaesthetics: a multicenter randomized controlled study in patients undergoing coronary artery bypass grafting with cardiopulmonary bypass. Eur J Anaesthesiol. 2007;24:323-31.

3. Symons JA, Myles PS. Myocardial protection with volatile anaesthetic agents during coronary artery bypass surgery: a meta-analysis. Br J Anaesth. 2006;97:127-36. 
4. Weber NC, Toma O, Wolter JI, Wirthle NM, Schlack W, Preckel B. Mechanisms of xenon and isoflurane induced preconditioning — a potential link to the cytoskeleton via the MAPKAPK-2/HSP27 pathway. Br J Pharmacol. 2005;146:445-55.

5. De Hert SG. Anesthetic preconditioning: how important is it in today's cardiac anesthesia. J Cardiothorac Vasc Anesth. 2006;20:473-6.

6. Belhomme D, Peynet J, Louzy M, Launay JM, Kitakaze M, Menasche P. Evidence for preconditioning by isoflurane in coronary artery bypass graft surgery. Circulation. 1999;100:340-4.

7. Weber NC, Toma O, Wolter JI, Obal D, Müllenheim J, Preckel B, et al. The noble gas xenon induces pharmacological preconditioning in the rat heart in vivo via induction of PKC-e and p38 MAPK. Br J Pharmacol. 2005;144:123-32.

8. Julier K, Da Silva R, Garcia C, Bestmann L, Frascarolo P, Zollinger A, et al. Preconditioning by sevoflurane decreases biochemical markers for myocardial and renal dysfunction in coronary artery bypass graft surgery: a double-blinded, placebo-controlled, multicenter study. Anesthesiology. 2003;98:1315-27.

9. De Hert SG, Van der Linden PJ, Cromheecke S, Meeus R, Nelis A, van Reeth V, et al. Cardioprotective properties of sevoflurane in patients undergoing coronary surgery with cardiopulmonary bypass are related to the modalities of its administration. Anesthesiology. 2004;101:299-310.

10. Fryer RM, Schultz JE, Hsu AK, Gross GJ. Importance of PKC and tyrosine kinase in single or multiple cycles of preconditioning in rat hearts. Am J Physiol Heart Circ Physiol. 1999;276:H1229-35.

11. Fräßdorf J, Ebel D, Weber NC, Preckel B, Schlack W. Sevoflurane induced preconditioning is blocked by aprotinin in rat hearts in vivo. Anesthesiology. 2006;105:A1086.

12. Michel P, Roques F, Nashef SAM. Logistic or additive EuroSCORE for high-risk patients? Eur J Cardiothorac Surg. 2003;23:684-7.

13. Weber NC, Stursberg J, Wirthle NM, Toma O, Schlack W, Preckel B. Xenon preconditioning differentially regulates p44/42 MAPK (ERK1/2) and p46/54 MAPK (JNK 1/2 and 3) in vivo. Br J Anaesth. 2006;97:298-306.

14. Schlack W, Preckel B, Barthel H, Obal D, Thämer V. Halothane reduces reperfusion injury after regional ischaemia in the rabbit heart in vivo. Br J Anaesth. 1997; 79:88-96.

15. Müllenheim J, Ebel D, Bauer M, Otto F, Heinen A, Fräßdorf J, et al. Sevoflurane confers additional cardioprotection after ischemic late preconditioning in rabbits. Anesthesiology. 2003;99:624-31.

16. Pouzet B, Lecharny JB, Dehoux M, Paquin S, Kitakaze M, Mantz J, et al. Is there a place for preconditioning during cardiac operations in humans? Ann Thorac Surg. 2002;73:843-8.

17. Murry CE, Jennings RB, Reimer KA. Preconditioning with ischemia: a delay of lethal cell injury in ischemic myocardium. Circulation. 1986;74:1124-36.

18. Tomai F, De Paulis R, Penta dP, Colagrande L, Caprara E, Polisca P, et al. Beneficial impact of isoflurane during coronary bypass surgery on troponin I release. G Ital Cardiol. 1999;29:1007-14.
19. Forlani S, Tomai F, De Paulis R, Turani F, Colella D, Nardi P, et al. Preoperative shift from glibenclamide to insulin is cardioprotective in diabetic patients undergoing coronary artery bypass surgery. J Cardiovasc Surg (Torino). 2004;45:117-22.

20. Piriou V, Mantz J, Goldfarb G, Kitakaze M, Chiari P, Paquin S, et al. Sevoflurane preconditioning at $1 \mathrm{MAC}$ only provides limited protection in patients undergoing coronary artery bypass surgery: a randomized bi-centre trial. Br J Anaesth. 2007; 99:624-31.

21. Tejero-Taldo IM, Gursoy E, Zhao TC, Kukreja RC. Alpha-adrenergic receptor stimulation produces late preconditioning through inducible nitric oxide synthase in mouse heart. J Mol Cell Cardiol. 2002;34:185-95.

22. Kehl F, Krolikowski JG, Mraovic B, Pagel PS, Warltier DC, Kersten JR. Hyperglycemia prevents isoflurane-induced preconditioning against myocardial infarction. Anesthesiology. 2002;96:183-8.

23. Kersten JR, Lowe D, Hettrick DA, Pagel PS, Gross GJ, Warltier DC. Glyburide, a $\mathrm{K}_{\mathrm{ATP}}$ channel antagonist, attenuates the cardioprotective effects of isoflurane in stunned myocardium. Anesth Analg. 1996;83:27-33.

24. Lange M, Smul TM, Blomeyer CA, Redel A, Klotz KN, Roewer N, et al. Role of the beta1-adrenergic pathway in anesthetic and ischemic preconditioning against myocardial infarction in the rabbit heart in vivo. Anesthesiology. 2006;105: 503-10.

25. Law-Koune JD, Raynaud C, Liu N, Dubois C, Romano M, Fischler M. Sevoflurane-remifentanil versus propofol-remifentanil anesthesia at a similar bispectral level for off-pump coronary artery surgery: no evidence of reduced myocardial ischemia. J Cardiothorac Vasc Anesth. 2006;20:484-92.

26. De Hert SG, Cromheecke S, ten Broecke PW, Mertens E, De Blier IG, Stockman BA, et al. Effects of propofol, desflurane, and sevoflurane on recovery of myocardial function after coronary surgery in elderly high-risk patients. Anesthesiology. 2003;99:314-23.

27. Alpert JS, Thygesen K, Antman E, Bassand JP. Myocardial infarction redefineda consensus document of The Joint European Society of Cardiology/American College of Cardiology Committee for the redefinition of myocardial infarction. J Am Coll Cardiol. 2000;36:959-69.

28. Selvanayagam JB, Pigott D, Balacumaraswami L, Petersen SE, Neubauer S, Taggart DP. Relationship of irreversible myocardial injury to troponin I and creatine kinase-MB elevation after coronary artery bypass surgery: insights from cardiovascular magnetic resonance imaging. J Am Coll Cardiol. 2005;45: 629-31.

29. Fellahi JL, Gue X, Richomme X, Monier E, Guillou L, Riou B. Short- and longterm prognostic value of postoperative cardiac troponin I concentration in patients undergoing coronary artery bypass grafting. Anesthesiology. 2003;99:270-4.

30. Landoni G, Biondi-Zoccai GGL, Zangrillo A, Bignami E, D'Avolio S, Marchetti C, et al. Desflurane and sevoflurane in cardiac surgery: a meta-analysis of randomized clinical trials. J Cardiothorac Vasc Anesth. 2007;21:502-11. 


\section{APPENDIX E1}

\section{Anesthesia, Surgery, and Study Protocol}

Acetylsalicylic acid therapy was discontinued 1 week prior to surgery; all other preoperative medications were continued until the morning of the operation. All patients were premedicated with $10 \mathrm{mg}$ diazepam the night before and the morning of the operation. Patient monitoring included continuous 5-lead electrocadiographic registration with ST-segment analysis (leads II and V5), pulse oximetry, invasive radial artery blood pressure measurement, CVP, pulmonary artery catheters with continuous mixed venous saturation and cardiac output measurement (CCOmbo, Edwards Lifescience, Irvine, CA), capnography, rectal temperature, and urine output.

After preoxygenation, anesthesia was induced by $20 \mu \mathrm{g}$ sufentanil and by starting a propofol target-controlled infusion with a target plasma concentration of $2.5 \mu \mathrm{g} / \mathrm{mL}$ plasma. Tracheal intubation was performed after muscle relaxation with $0.1 \mathrm{mg} / \mathrm{kg}$ pancuronium bromide. Continuous infusion of sufentanil $\left(0.3 \mu \mathrm{g} \cdot \mathrm{kg}^{-1} \cdot \mathrm{h}^{-1}\right)$ and propofol target-controlled infusion were used for maintenance of anesthesia.

Standard median sternotomy and pericardiotomy were performed and the left internal thoracic artery was dissected free. After systemic heparinization (300 IU/kg with additional doses to reach target-activated coagulation time $>$ $400 \mathrm{~s}$ ), arterial and venous cannulae for CPB were inserted and secured in place. A tip manometer (MillarTip catheter, Millar Instruments, Houston, TX) was inserted into the left ventricle via the right superior pulmonary vein. The pressure signal was digitally recorded on a computer system (PowerLab 4/30, ADinstruments, Spechbach, Germany). All hemodynamic recordings were obtained during respiratory arrest without positive end-expiratory pressure.

After registration of baseline values, a first sample of the right atrium was obtained and immediately frozen in liquid nitrogen and stored at $-80^{\circ} \mathrm{C}$ until further processing for immunoblotting. Sevoflurane preconditioning was than induced in the SEVO-I and SEVO-II groups. Therefore, the ventilator was set to a fresh gas flow of $12 \mathrm{~L} / \mathrm{min}\left(\mathrm{FiO}_{2} 0.7\right)$, and the vaporizer was set to reach an end-tidal concentration of 2
Vol\%. After 5 minutes, the vaporizer was set to 0 to wash out sevoflurane. In the SEVO-II group, this maneuver was repeated after 5 minutes. Ten minutes after the last sevoflurane administration, or the corresponding time point in the control group, we obtained a second sample of the right atrium for immunoblotting. Then CPB was started and the aorta was crossclamped. Cardiac arrest was achieved by warm blood cardioplegia $\left(34^{\circ} \mathrm{C}\right)$. All distal anastomoses were performed during aortic crossclamping with repeated warm blood cardioplegia. The proximal anastomoses were performed during reperfusion of the heart with partial clamping of the aorta. After completion of coronary artery grafting and rewarming of the patient (rectal temperature $36^{\circ} \mathrm{C}$ ), $\mathrm{CPB}$ was discontinued and heparin was antagonized by protamine (in the ratio $1.5 \mathrm{mg}$ per $100 \mathrm{IU}$ heparin given). No patient received aprotinin. The heart was paced in atrioventricular sequence mode with a frequency of 90 beats $/ \mathrm{min}$. According to the study protocol, norepinephrine was used to keep MAP above $70 \mathrm{~mm} \mathrm{Hg}$, and dobutamine was used to maintain CI above $2.5 \mathrm{~L} \cdot \mathrm{min}^{-1} \cdot \mathrm{m}^{-2}$. All hemodynamics were measured 3 and 10 minutes after termination of CPB, and then the MillarTip catheter was removed. An overview of the time points of hemodynamic measurements and blood sampling is given in Figure 1.

All operations were performed by the same surgeon, and anesthesia was performed by 2 cardiothoracic anesthesiologists. Patients, surgeon, and perfusionists were blinded regarding the enrollment into the study groups. After surgery, patients were transferred to the ICU and received routine therapy, including fast weaning from the ventilator. All decisions regarding medical care on the ICU and the ward after the operation were made by physicians and nurses blinded to the study protocol. Duration of postoperative intubation was defined as time between end of operation and extubation in the ICU (in minutes). Length of stay in ICU was defined as time between arrival at the ICU and transfer to the ward (in hours). Length of stay in hospital was defined as the time between day of operation and discharge from hospital to home or rehabilitation facility (in days). 
TABLE E1. Global hemodynamics

\begin{tabular}{|c|c|c|c|c|c|c|c|c|c|c|c|}
\hline & $\begin{array}{c}\text { Baseline } \\
\text { (T1) }\end{array}$ & $\begin{array}{c}\text { SEVO-I } \\
\text { (T2) } \\
\end{array}$ & $\begin{array}{c}\text { WASH-I } \\
\text { (T3) } \\
\end{array}$ & $\begin{array}{c}\text { SEVO-II } \\
\text { (T4) }\end{array}$ & $\begin{array}{c}\text { WASH-II } \\
\text { (T5) } \\
\end{array}$ & $\begin{array}{c}\text { Post-CPB } \\
\text { (T7) }\end{array}$ & $\begin{array}{l}\text { End } \\
\text { (T9) }\end{array}$ & $\begin{array}{c}4 \mathrm{~h} \\
\text { post-CPB } \\
(\mathrm{T} 12) \\
\end{array}$ & $\begin{array}{c}8 \mathrm{~h} \\
\text { post-CPB } \\
(\mathrm{T13}) \\
\end{array}$ & $\begin{array}{c}12 \mathrm{~h} \\
\text { post-CPB } \\
(\mathrm{T} 14) \\
\end{array}$ & $\begin{array}{c}24 \mathrm{~h} \\
\text { post-CPB } \\
(\mathrm{T} 15) \\
\end{array}$ \\
\hline \multicolumn{12}{|l|}{$\operatorname{HR}(1 / \mathrm{min})$} \\
\hline $\mathrm{CON}$ & $69 \pm 17$ & & & & $76 \pm 20$ & $97 \pm 10 \dagger$ & $95 \pm 10 \dagger$ & $96 \pm 11 \dagger$ & $92 \pm 9 \dagger$ & $93 \pm 8 \dagger$ & $89 \pm 7 \dagger$ \\
\hline SEVO-I & $66 \pm 11$ & $79 \pm 16$ & & & $75 \pm 9$ & $97 \pm 11 \dagger$ & $93 \pm 8 \dagger$ & $98 \pm 13 \dagger$ & $99 \pm 18 \dagger$ & $99 \pm 15 \dagger$ & $94 \pm 12 \dagger$ \\
\hline SEVO-II & $64 \pm 18$ & $65 \pm 13$ & $66 \pm 15$ & $66 \pm 15$ & $69 \pm 13^{*}$ & $96 \pm 9 \dagger$ & $89 \pm 9 \dagger$ & $90 \pm 6 \dagger$ & $90 \pm 8 \dagger$ & $91 \pm 7 \dagger$ & $90 \pm 11 \dagger$ \\
\hline \multicolumn{12}{|c|}{ MAP (mm Hg) } \\
\hline $\mathrm{CON}$ & $91 \pm 18$ & & & & $74 \pm 20$ & $75 \pm 16$ & $85 \pm 12$ & $84 \pm 9$ & $80 \pm 13$ & $79 \pm 5$ & $89 \pm 13$ \\
\hline SEVO-I & $95 \pm 17$ & $69 \pm 14 \dagger$ & & & $85 \pm 11$ & $75 \pm 14 \dagger$ & $82 \pm 14$ & $86 \pm 16$ & $90 \pm 9$ & $77 \pm 12$ & $84 \pm 11$ \\
\hline SEVO-II & $83 \pm 12$ & $69 \pm 6$ & $77 \pm 12$ & $68 \pm 10 \dagger$ & $81 \pm 10$ & $85 \pm 13$ & $90 \pm 10$ & $77 \pm 7$ & $80 \pm 9$ & $82 \pm 13$ & $90 \pm 11$ \\
\hline \multicolumn{12}{|c|}{ PCWP (mm Hg) } \\
\hline $\mathrm{CON}$ & $9 \pm 5$ & & & & $5 \pm 3$ & $8 \pm 6$ & $8 \pm 3$ & $14 \pm 4$ & $15 \pm 4$ & $13 \pm 4$ & $13 \pm 2$ \\
\hline SEVO-I & $9 \pm 4$ & $7 \pm 4$ & & & $7 \pm 4$ & $7 \pm 3$ & $9 \pm 4$ & $13 \pm 4$ & $13 \pm 2$ & $13 \pm 2$ & $12 \pm 2$ \\
\hline SEVO-II & $12 \pm 4$ & $10 \pm 4$ & $10 \pm 4$ & $10 \pm 4$ & $10 \pm 5^{*}$ & $13 \pm 6$ & $12 \pm 5$ & $13 \pm 3$ & $13 \pm 4$ & $13 \pm 2$ & $13 \pm 3$ \\
\hline \multicolumn{12}{|c|}{$\mathrm{CI}\left(\mathrm{L} \cdot \mathrm{min}^{-1} \cdot \mathrm{m}^{-2}\right)$} \\
\hline $\mathrm{CON}$ & $2.4 \pm 0.4$ & & & & $2.6 \pm 1.1$ & $2.8 \pm 1.1$ & $2.7 \pm 0.6$ & $2.7 \pm 0.4$ & $2.8 \pm 0.5$ & $2.9 \pm 0.6$ & $3.3 \pm 0.5$ \\
\hline SEVO-I & $2.2 \pm 0.6$ & $2.7 \pm 0.7$ & & & $2.7 \pm 0.8$ & $3.0 \pm 1.1$ & $3.0 \pm 0.9$ & $3.3 \pm 0.6$ & $3.4 \pm 0.8 \dagger$ & $3.3 \pm 1.0 \dagger$ & $3.4 \pm 0.9 \dagger$ \\
\hline SEVO-II & $2.5 \pm 0.9$ & $2.5 \pm 0.6$ & $2.5 \pm 0.5$ & $2.4 \pm 0.5$ & $2.7 \pm 0.5$ & $2.4 \pm 0.6$ & $2.8 \pm 0.5$ & $3.3 \pm 0.8$ & $3.6 \pm 0.7^{*}$ & $3.3 \pm 0.5 \dagger$ & $3.4 \pm 0.5 \dagger$ \\
\hline
\end{tabular}

$H R$, Heart rate; $M A P$, mean arterial pressure; $P C W P$, pulmonary artery wedge pressure; $C I$, cardiac index; $C O N$, control group. For explanation of the time points and groups see Figure 1; data are mean \pm standard deviation. ${ }^{*} P<.05$ versus control group; $\nmid P<.05$ versus baseline.

TABLE E2. Laboratory testing

\begin{tabular}{|c|c|c|c|c|c|c|c|c|}
\hline & $\begin{array}{l}\text { Baseline } \\
\text { (T1) }\end{array}$ & $\begin{array}{c}10 \mathrm{~min} \\
\text { post-CPB (T7) }\end{array}$ & $\begin{array}{l}\text { Arrival on } \\
\text { ICU (T10) }\end{array}$ & $\begin{array}{c}4 \mathrm{~h} \text { post-CPB } \\
\text { (T12) }\end{array}$ & $\begin{array}{c}12 \text { h post-CPB } \\
\text { (T14) }\end{array}$ & $\begin{array}{c}24 \text { h post-CPB } \\
\text { (T15) }\end{array}$ & $\begin{array}{c}48 \text { h post-CPB } \\
\text { (T16) }\end{array}$ & $\begin{array}{c}72 \text { h post-CPB } \\
\text { (T17) }\end{array}$ \\
\hline \multicolumn{9}{|l|}{ CK (U/L) } \\
\hline $\mathrm{CON}$ & $57 \pm 25$ & $\mathrm{n} / \mathrm{a}$ & $576 \pm 252$ & $605 \pm 244$ & $595 \pm 241$ & $598 \pm 328$ & $629 \pm 572$ & $456 \pm 373$ \\
\hline SEVO-I & $63 \pm 29$ & $\mathrm{n} / \mathrm{a}$ & $503 \pm 208$ & $569 \pm 186$ & $644 \pm 225$ & $631 \pm 206$ & $406 \pm 172$ & $233 \pm 108$ \\
\hline SEVO-II & $69 \pm 36$ & $\mathrm{n} / \mathrm{a}$ & $576 \pm 282$ & $609 \pm 339$ & $595 \pm 269$ & $701 \pm 486$ & $442 \pm 265$ & $213 \pm 101$ \\
\hline \multicolumn{9}{|c|}{ CK-MB (U/L) } \\
\hline $\mathrm{CON}$ & $10.8 \pm 2.3$ & $\mathrm{n} / \mathrm{a}$ & $38.1 \pm 19.1$ & $26.8 \pm 11.1$ & $21.6 \pm 8.1$ & $15.7 \pm 12.9$ & $14.3 \pm 13.8$ & $10.8 \pm 9.0$ \\
\hline SEVO-I & $8.2 \pm 8.2$ & $\mathrm{n} / \mathrm{a}$ & $38.6 \pm 12.8$ & $27.5 \pm 10.5$ & $23.7 \pm 8.4$ & $21.8 \pm 10.3$ & $12.2 \pm 8.5$ & $6.6 \pm 3.5$ \\
\hline SEVO-II & $5.2 \pm 2.9$ & $\mathrm{n} / \mathrm{a}$ & $28.6 \pm 16.1$ & $22.4 \pm 15.2$ & $18.9 \pm 10.2$ & $20.2 \pm 17.4$ & $8.8 \pm 8.1$ & $4.9 \pm 5.3$ \\
\hline \multicolumn{9}{|c|}{ BNP (pg/mL) } \\
\hline $\mathrm{CON}$ & $17.2 \pm 9.9$ & $32.6 \pm 14.1$ & $38.8 \pm 14.1$ & $52.6 \pm 25.4$ & $90.0 \pm 34.4$ & $141.3 \pm 60.1^{*}$ & $133.1 \pm 71.2^{*}$ & $146.1 \pm 104.0^{*}$ \\
\hline SEVO-I & $14.3 \pm 10.4$ & $33.6 \pm 27.8$ & $35.5 \pm 22.4$ & $45.7 \pm 31.9$ & $72.0 \pm 51.8$ & $158.5 \pm 77.6^{*}$ & $153.2 \pm 70.0^{*}$ & $149.9 \pm 80.8^{*}$ \\
\hline SEVO-II & $34.8 \pm 30.5$ & $37.7 \pm 29.4$ & $48.7 \pm 34.4$ & $59.7 \pm 36.7$ & $141.3 \pm 84.2$ & $233.5 \pm 155.3^{*}$ & $239.1 \pm 120.8^{*}$ & $247.2 \pm 123.5^{*}$ \\
\hline
\end{tabular}

$C K$, Creatine kinase; $C K-M B, \mathrm{MB}$ isoform from $\mathrm{CK} ; B N P$, brain natriuretic peptide; $I C U$, intensive care unit; $C P B$, cardiopulmonary bypass; $C O N$, control group. For explanation of the time points and groups see Figure 1; data are mean \pm standard deviation. $* P<.05$ versus baseline. 